\title{
Implications of Climate Change for Agricultural Sector Performance in Africa: Policy Challenges and Research Agenda
}

Rashid M. Hassan

Centre for Environmental Economics and Policy Analysis in Africa (CEEPA), University of Pretoria

Journal of African Economies, 2010 


\title{
Implications of Climate Change for Agricultural Sector Performance in Africa: Policy Challenges and Research Agenda
}

\begin{abstract}
The paper analyzed how climate change (CC) has shaped African agriculture in the past and how it might impact on African farm economies in the future and what adaptation strategies African farmers have adopted to cope with these changes. The analyses covered all key farming systems and agro-climates of Africa in 11 countries in which data was collected from over 10,000 farm household surveys. Results provided evidence that African agriculture and the welfare of its rural population are vulnerable to CC. The highest risk of future CC damages is associated with specialized crop and livestock farming (mono systems) particularly under dryland conditions in arid and semi-arid regions. This indicates how difficult it is to achieve an African green revolution under the current high reliance on dryland systems (more than 95\% of the land) given predicted harsh future climates (warmer and dryer projections) for most of the dryland areas in Africa. It will require substantial public and private investments in expanding irrigation and development of crop varieties and animal breeds that are tolerant to heat, water and low fertility stresses, and in building roads and marketing infrastructures that will improve access to critical inputs (e.g. fertilizer) and output trade. This essentially requires mainstreaming climate sensitivity as an integral component of all agricultural and broader economic development planning and policy design.

While the expected damages are large many farming systems and communities in Africa face serious limiting conditions which reduce their ability to adapt and hence increase their vulnerability. Among the key factors found to constrain African farmers' ability to adopt effective adaptation measures are poor access to information, capital, technology and markets. Policies aimed at promoting farm-level adaptation need to emphasize the critical role of farmers' education; provision of improved climate, production and market information and the means to implement adaptations through affordable credit facilities. Other needed public interventions to help promote adaptation measures and reduce vulnerability include insurance against climate risks to farmers and provision of safety nets.
\end{abstract}




\section{Implications of Climate Change for Agricultural Sector Performance in Africa: Policy Challenges and Research Agenda}

\section{R M Hassan, CEEPA, University of Pretoria}

\section{Preamble}

No doubt our level of awareness and understanding of the climate change (CC) phenomena and their impacts on our planet earth and its inhabitants have significantly improved over the past two decades. There has also been growing attention to and concerns about the consequences of climate change among almost all governments in the world. We remain however with some key uncertainties and gaps of knowledge associated with the complex dynamics between CC, its anthropogenic (human activity) drivers and life on earth including human wellbeing presenting major challenges to present day science and policy making. This is particularly the case in developing countries where efforts and investment levels in scientific research and action programs to better understand and respond to CC continue to be low and the capacity to survive CC vagaries and take advantage of its potential benefits remains consequently very weak. Africa and especially its farming communities and rural population stand out as one clear case of very high vulnerability to $\mathrm{CC}$ and its variance.

The Synthesis Report of the forth assessment of the Intergovernmental Panel on Climate Change (IPCC) explains how hard it is to find evidence of negative consequences of CC on the world agricultural productivity in aggregate agricultural statistics. One reason is the positive gains from global warming observed in the temperate regions (e.g. North America and Europe) due to reduced risk of frost and longer growing season duration. The other important reason is the fact that world agriculture in general but particularly in temperate regions had witnessed noticeable increases in productivity of most crops as a result of major technological advances (breeding and improved fertility and pest and disease management) (IPCC, 2007). Although there is some evidence that agriculture in 
temperate regions of the world have benefited in some ways from global warming the same IPCC report states with high confidence that "agricultural production and food security (including access to food) in many African countries and regions are likely to be severely affected by climate change and climate variability" (IPCC, 2007a). This is due to the fact that African economies and the livelihoods of its population are highly dependant on agriculture which is mainly practiced in already harsh climatic conditions (e.g. high temperature, marginal environments, and considerable water stress). It is also important to note that rural people and agricultural production in Africa rely mainly on rainfall for water supply (with as little as less than $4 \%$ of cultivated land under irrigation (IAC, 2004, World Bank, 2008) and hence are very vulnerable to fluctuations in precipitation levels and distribution.

Although Africa's contribution to green house gas (GHG) emissions (the cause of global warming) is significantly lower than industrial world, it has the lowest adaptive capacity because of the many non-climate factors that confound the adversities of CC (low technology, poor access to capital, infrastructure and markets, high poverty and deep social and political chaos). Agriculture however remains critical for most African countries contributing an average of 15\% of gross domestic product - GDP in 2006 (reaching up to 50\% of GDP in many countries) and the main source of employment for the vast majority of the population (World Bank, 2008).

There is sufficient evidence that the world has been witnessing long term changes in climate patterns and variability with rapid acceleration in recent decades. Considerable shifts in long term temperature and rainfall averages, sea levels, frequency and intensity of draughts and floods, and their variances have been observed (IPCC, 2007). Modeling and observational research have also provided ample evidence that the experienced long term shifts in climate parameters have impacted substantially on many aspects of life on earth. The causal relationship between anthropogenic drivers (green house gas emissions) and CC has also been established albeit with lower certainty due to the complex and intricate interactions and feedback mechanisms between climate and non-climate spheres 
(IPCC, 2007, Stern, 2007). All of the above have been observed to happen with important regional variations and differential impacts.

State of knowledge at regional scale such as for Africa is however limited. Very few studies have so far have investigated the economics of CC impacts on and potential adaptation measures for African agriculture. Most of existing impact assessment knowledge comes from modeling the response of few selected crops to CC based on results of controlled agronomic experiments and crop growth simulation modeling (Kurukulasuriya and Rosenthal, 2003). On the other hand, research on farmers' adaptations to CC is seriously lacking (IPCC, 2007a). Even predictions of what future climate scenarios will obtain for Africa are based on global climate simulation models (GCCM) with little effort on downscaling to the regional level (Hulme et al., 1996; Rinke et al., 2007).

The present paper synthesizes methods and results of recent continent-wide research efforts attempting to contribute to bridging some of these knowledge gaps. The said studies analyzed how CC has shaped African agricultural practices in the past and how it might impact on African farm economies in the future and what adaptation strategies African farmers have adopted to cope with these changes. The studies were based on collaborative research efforts funded by the Global Environmental Facility (GEF) and led and coordinated by the Centre for Environmental Economics and Policy in Africa (CEEPA) of the University of Pretoria and the World Bank (WB). The GEF project was implemented in 11 countries in which data was collected from over 10,000 farm household surveys and covered all key farming systems and agroclimates of Africa. Details of the technical contents and empirical results of these efforts are found in many published sources (Hassan, Dinar and Mendelsohn, 2008; Dinar et al., 2008; www.ceepa.co.za/Climate_Change/project.html). This work has also been extensively cited in Chapter 9 (Africa) of the Fourth Assessment Report of IPCC (IPCC, 2007a).

The paper is organized in five sections. The next section charts the basic picture of the links between CC and agricultural performance in Africa. Section three presents methods 
and results of attempts to measure the economic impact of CC on African farm economies and how that is distributed between farming systems, countries and regions. Results of research analyzing farmers' adaptation responses to CC are presented and discussed in section four and section five concludes distilling policy implications and challenges for future research on CC and its impacts on African agriculture.

\section{Observed climate change patterns and impacts on African agriculture}

The Fourth Assessment Report (FAR) of IPCC confirms a trend of greater warming since the 1960s across the African continent with some regional differences (IPCC, 2007b). A rising continental temperature trend since the early 70s can obviously be discerned in Figure 1. The FAR asserts relatively faster warming in tropical rain forest and southern regions compared to the rest of Africa. Observed regional variations with respect to rainfall patterns are a bit more complicated (Figure 2). Between 1960 and 1998 a decline in mean annual precipitation of between $20 \%$ to $40 \%$ has been noted in West Africa (Sahel) compared to a $2 \%$ to $4 \%$ decline in tropical rain forest regions whereas the Guinean Coast experienced a 10\% increase in rainfall over the past 30 years. East Africa

on the other hand experienced a dipole pattern of higher rain in the north and declining trends in the south. Although no long term trend in mean annual rainfall was observed in Southern Africa inter-annual variability has increased since 1970 showing evidence for change in seasonality and extreme weather events (IPCC, 2007).

In addition to the evidence on more intense droughts inter-annual lake-level fluctuations associated with long term changes in climate are observed such as the warming of surface and deep water temperatures of the major East African lakes since 1900 (IPCC, 2007). Some changes in hydrology and runoff have also been observed in southern Africa, Ethiopia, Kenya and Tanzania as well as other parts of the continent (IPCC, 2007). 


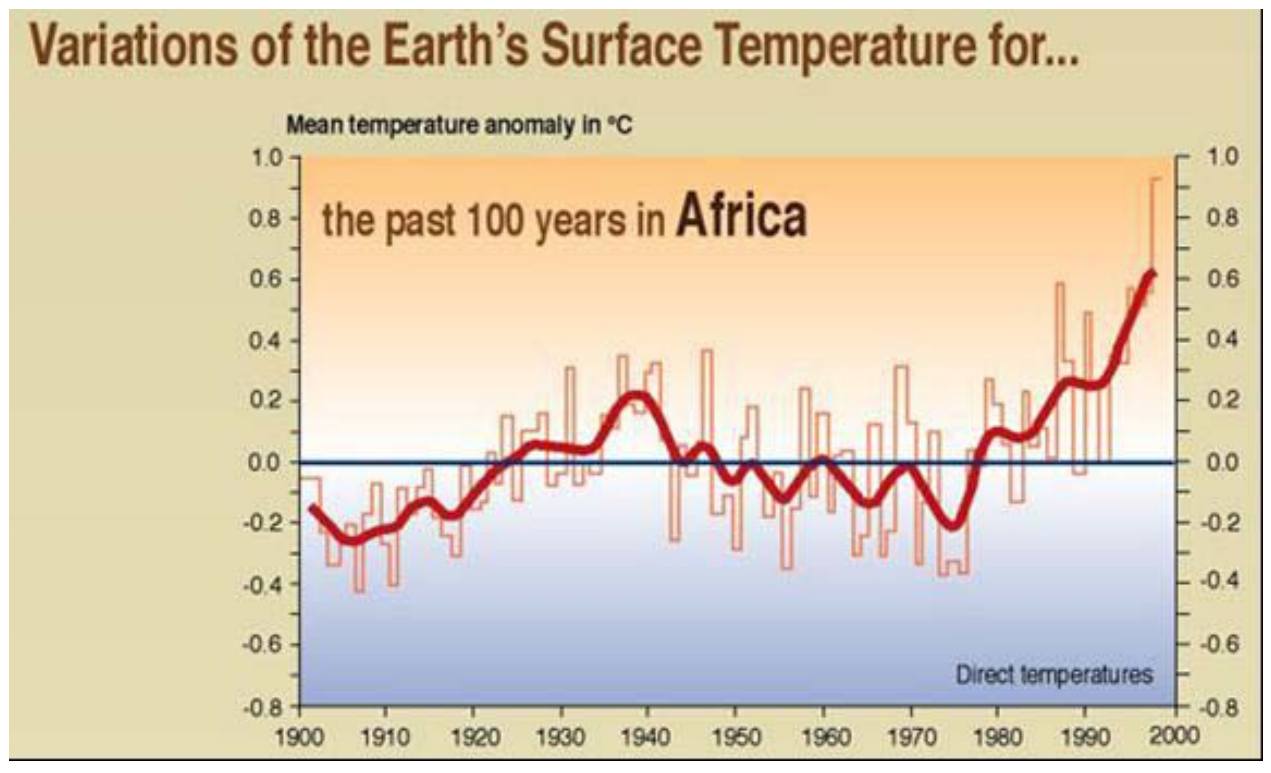

Figure 1. Variations of the Earth's Surface Temperature for the past 100 years in Africa (UNEP Grid Arendal, 2002)

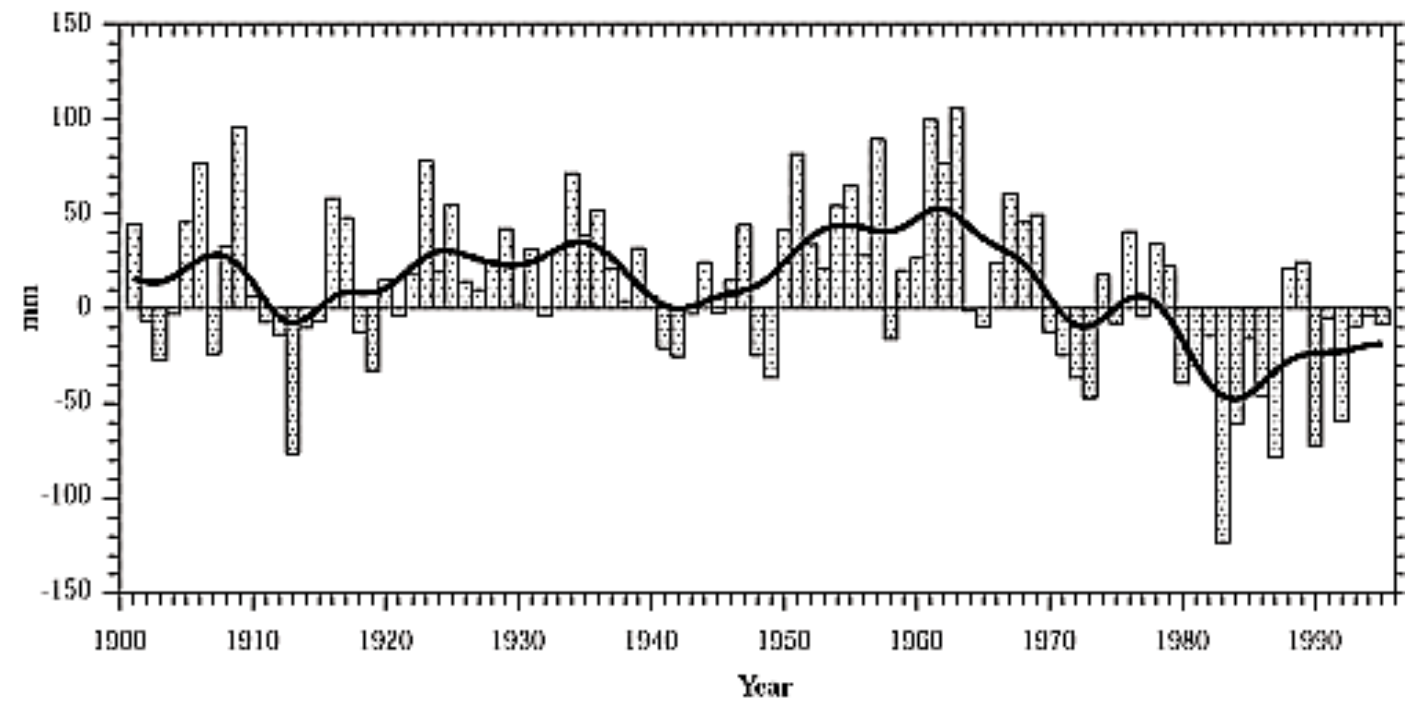

Figure 2: Observed annual precipitation changes for the Africa region (IPCC, 2001)

Although the above climate trends information is of good credibility, unfortunately our knowledge of their economic impacts is seriously limited. Figure 3 shows a sharp decline in per capita food production for Africa since the early 1970s with some recovery after the mid 1980s in contrast to a steady improvement in the world index. If one wants to 
correlate the trend in Africa's per capita food production to climate patterns depicted in figures 1 and 2 over the period since 1970s one will find it very hard to establish clear association even under the assumption that all other things (i.e. non-climate drivers) remain the same. That is because although one can see a strong direct correlation between the falling index and declining rainfall and increasing temperature over some range (i.e. up to the mid 1980s) the food index seems to respond more to improved rainfall trends more than to the negatives of warmer temperature beyond that point. Of course it is easy to attribute things to fluctuations in the many powerful non-climate drivers (suggesting some improvements).

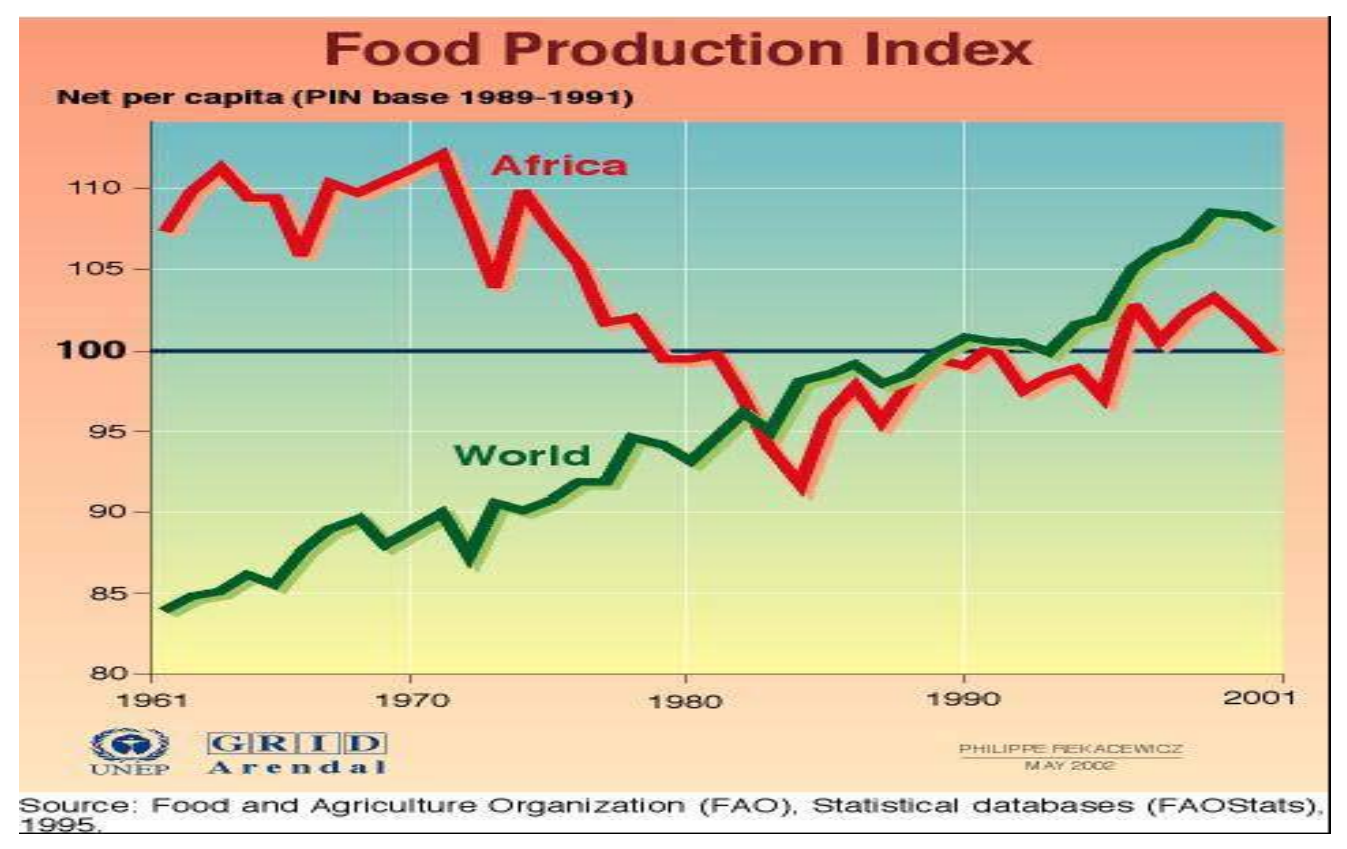

Figure 3: Food production index in Africa (UNEP Grid Arendal, 2002)

Unfortunately not very much information and knowledge is coming from climate impacts' research to help explain these recent trends. Apart from some agronomic research based on modeling exercises mainly focused on predicting impacts of future climate scenarios, very little has been done on documenting and analyzing observed evidence of past impacts of CC on African agriculture. One source to cite on observed negative impacts of CC on agricultural productivity in Africa attributes an observed decline in production of groundnuts in the Sahel to warm and dry conditions (Van Duivenbooden et al., 2002 cited in Rinke et al., 2007). Most existing evidence of 
observed CC impacts on agriculture in Africa comes from studies on vulnerability to extreme events such as floods and droughts and hydrological consequences for water resources' stresses. Knowledge on the magnitude of the overall economic damages inflicted by CCon African agriculture however remains limited.

While the figures showing trends in drought incidence and people affected (Figures 4 and 5) do not provide a neat correlation with per capita food index trend, they provide useful information on the vulnerability of African people to climate variability. Africa bears a significant share of all draughts in the world and the number of people affected by droughts in Africa is almost equal to the affected world totals in many years. The World Water Forum (WWF, 2000) estimates that one third of Africa's population live in drought-prone areas. Tarhule and Lamb (2003) suggest that Africa lost several hundred million US dollars in damages caused by the mid 1980's droughts. Droughts are observed to mainly affect Sahel, Horn and southern Africa regions (IPCC, 2007a). About 200 million people in Africa (25\% of total population) currently face high water stress (IPCC, 2007).
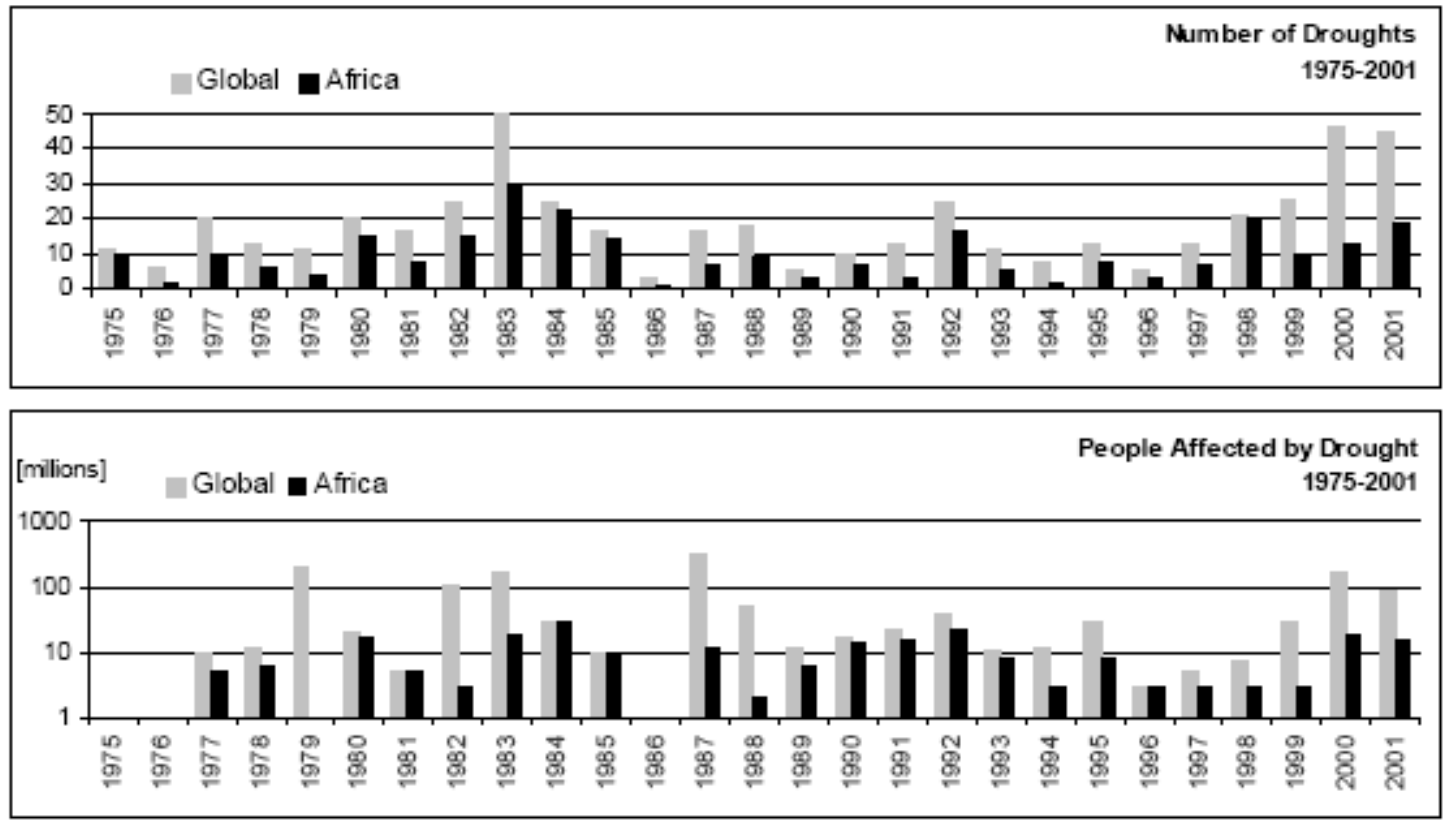

Figure 4: Number of drought events (top) and population affected by drought (bottom) globally (grey bars) and in Africa (black bars) during 1975-2001 (x-axis). People affected 
are defined as requiring immediate assistance (OFDA/CRED International Disaster Database at www.cred.be/emdat).

It is very clear that much more effort and research is needed to understand and quantify climate damages on vulnerable natural and managed African systems, especially agriculture where the biggest impacts are expected. The next section makes an attempt to contribute to filling knowledge gaps in this area based on recent multi-country Africawide collaborative research efforts.

\section{Measuring economic impacts of CC on African agriculture}

\subsection{Approaches to measuring CC impacts on agriculture}

CC takes place over a very long time horizon. One way to capture its impacts is therefore to have a long time series data covering decades. While long time series may be available for climate attributes, records over very long periods on changes in revealed economic behavior such as production and consumption decisions for the same sample do not exist even in countries with well organized information systems. Some alternative approaches have been attempted to analyze CC impacts such as simulation modeling methods and empirical studies based on cross-section variations.

Crop growth models based on controlled agronomic experiments to determine the response of specific crops and crop varieties to different climatic and other conditions are among the most commonly used simulation approaches to predict impacts of CC on agriculture. These models can also handle impacts of changes in management practices such as timing of operations, choice of crops, irrigation and use of fertilizers (Kaiser et al., 1993; Adams, 1999; Shimmelpfenning et al. 1996). Agronomic models are useful for understanding the biophysical responses as well as indicating various technological and adaptation options that would offset the negative effects of climate change and positively increase yields. Studies that applied crop simulation modeling to estimate CC impacts on African agriculture include: Muchena (1994), Magadza (1994), Makadho (1996), Schulze et al. (1993) and Du Toit et al (2002). A study by Mendelsohn et al. (2000b) made an 
attempt to assess likely impacts of CC on African agriculture but relied on experimental data and models from the US.

Using results from agronomic models, economic impacts such as changes in area allocations, output supply and resulting changes in prices by crop and region are then estimated. The economic component of these models attempts to optimize consumer and producer welfare subject to climatic and other factors (Easterling et al., 1993; Darwin et al., 1994; Chang, 2002; Kumar and Parikh, 2001; Iglesias et al. 1999; Rosenzweig and Parry, 1994). These models suffer from the limitation that the agronomic component fails to account for economic considerations and limitations in human capital and other resources that affect actual farm-level adaptation decisions hence either overestimating damages or underestimating the potential benefits of CC leading to potential biases in economic analyses based on these estimates. Add to this the high costs associated with experimental agronomic research and the difficulty with generalizing inferences based on results from few experimental sites to large areas and diverse agricultural production systems (Mendelsohn, 2000; Adams 1999).

Another example of structural models is the Future Agricultural Resources Model (FARM) which makes use of geographic information systems (GIS) to link climatically derived land classes with other inputs and agricultural outputs in a computable general equilibrium (CGE) model of the world. The GIS component characterises regional differences in land, climate, water and agricultural suitability. Changes in climate are assumed to alter agricultural potentials of a given area by shifting regional land class and water characteristics. The resulting economic changes and effects on regional and global production and prices are then estimated by the CGE component (Adams et al. 1998; Darwin et al., 1994, 1995). The FARM model captures interactions between farmers and downstream consumers (both domestic and foreign) of agricultural products that are likely to occur under climate change (Darwin, 1999).

The agro-ecological zone (AEZ) model is another simulation modeling approach that relies heavily on natural science relationships to predict land utilization types based on 
combinations of existing technology, soil and climate to determine which crops are suitable for each cell. Based on this, the AEZ model can simulate the impacts of changes in temperature and precipitation on potential agricultural output and cropping patterns at a global scale. One major advantage of the AEZ model, is the widespread coverage of developing countries, where little climate research has been done, and where data constraints may make the use of other methods difficult (Mendelsohn, 2000).

Integrated assessment models (IAMs) are also used for predicting climate change impacts. Using projections of economic development over the next century, global warming IAMs can make predictions of future greenhouse gas concentrations (Crosson and Rosenburg, 1993; Adams et al., 1995; Rosenzweig and Parry, 1993). Among the studies that assessed vulnerability of agricultural production and food security to CC in Africa are Yates and Strzepek (1998), Downing (1992), Benson and Clay (1998), Desanker (2002), Fischer and Van Velthuizen (1996), Thornton et al. (2006), Onyeji and Fischer (1994).

One other commonly used approach to measuring impacts of CC on agriculture is what is known as the cross-section (Ricardian) model pioneered by Mendelsohn, Nordhaus and Shaw (1994). This approach was widely applied to analyze the relationship between net revenue from crops and climate controlling for other key factors (Mendelsohn and Nordhaus, 1996; Sanghi et al., 1998; Mendelsohn, 2000, Mendelsohn and Dinar, 1999, 2003; Kumar and Parikh, 2001). The method was attempted in few case studies in Africa before the GEF study was implemented (Gbetibouo and Hassan, 2005; Deressa, Hassan and Poonyth, 2005; Molua, 2002). The Ricardian approach was the main method adapted in the GEF studies to conduct, for the first time multi-country analyses of impacts of CC on African crop and livestock agriculture using African data as documented in the following section.

\subsection{Methods of the GEF multi-country studies}

This study used both crop water response (CROPWAT) simulation modeling (results of which are not reported here) and various adapted versions of the cross-section Ricardian 
method. The original Ricardian method assesses performance of farms by quantifying impacts on agricultural productivity across the landscape revealing the effects of variations between different climate zones. Measured changes in farm performance are used to estimate long-run sensitivity of farm performance to climate. The cross-section method builds on the early observation made by David Ricardo (1815) suggesting that farmland rents capture long-term farm productivity and value. The model therefore postulates that farmland value $(V)$, reflects the present value of future net farm revenue from all activities:

$V=\int R_{t} e^{\delta t} d t=\int\left[\sum P_{i t} Q_{i t}(X, C)-\sum P_{x t} X_{t}\right] e^{\delta t} d t$

Where $R$ measures net revenue per hectare, $P_{i}$ the market price of product $i, Q_{i}$ is quantity of product $i, X$ is a vector of purchased inputs, $C$ is a vector of climate (and other) variables, $P_{x}$ is a vector of input prices, $\mathrm{t}$ is time, and $\delta$ is the discount rate. This model assumes that farmers choose the mix of products to be grown and inputs in order to maximize net farm revenue using a production function combining economic inputs subject to climate, soils and other conditions. Optimization rules lead to a net revenue response function that varies with input and product prices conditional on climate, soil and other externally determined factors.

Using the observed locus of these maximum profits for all farmers one can estimate an average aggregate net farm response surface as a function of observed levels of input and output prices, climate and other exogenous factors that can not be controlled or altered by farmers. Since climate factor inputs in farmers' production function such as precipitation and temperature are not acquired through a market transaction and hence have no market prices, one can consider the net revenue response function measured over a range of climates a reduced form hedonic price model. The model can thus be used to value climate attributes in terms of their marginal effects on net revenue as a proxy measure of change in farmers' welfare. This is the principle idea behind using the Ricardian crosssection approach to measure economic impacts of CC. 
The empirical specification of standard Ricardian model follows a quadratic formulation of climate variables measured by $\mathrm{C}$ to capture the non-linear shape of the relation between climate and net revenue:

$$
R=\beta_{0}+\beta_{1} C+\beta_{2} C^{2}+\beta_{3} P+\beta_{4} G+u
$$

Where $u$ is the error term, $\mathrm{C}$ refers to temperature and rainfall, $\mathrm{P}$ is the set of prices and $\mathrm{G}$ is a set of other exogenous factors. The marginal impact of a climate variable $\left(C_{i}\right)$ on net farm revenue evaluated at the mean of that variable is:

$$
E\left[\frac{d R}{d C_{i}}\right]=\beta_{1, i}+2 * \beta_{2, i} * E\left[C_{i}\right]
$$

Welfare changes $(\Delta \mathrm{U})$ resulting from a change in climate from $C_{0}$ to $C_{1}$ can be measured as:

$$
\Delta U=R^{*}\left(C_{1}\right)-R^{*}\left(C_{0}\right)
$$

CC that increase net farm income would be beneficial and would be harmful to farmers' welfare if they lead to decreases in net farm income.

The Ricardian model automatically captures farmers' adaptation responses assuming that cross-section variations reflect different states of long-term equilibria (inter-temporal changes). The model controls for the effects of farm and household attributes (size, soil type, market access, assets, current technology, etc.) but does not account for future change in technology, policies and institutions, which are important to keep in mind when interpreting results. Among its other limitations is the fact that it may overestimate welfare effects under large price shifts that can have offsetting effects to CC damages. The Ricardian framework also does not account for the effect of factors that do not vary across space such as $\mathrm{CO}_{2}$ concentrations that can be beneficial to crops ${ }^{1}$.

\footnotetext{
${ }^{1}$ The GEF studies made attempts through crop water response models (CROPWAT) to evaluate the effects of $\mathrm{CO}_{2}$ concentrations (Durand, 2006; Wahaj et al., 2006).
} 


\subsection{The data and model variables}

The GEF study covered eleven African countries: Burkina Faso; Cameroon; Egypt; Ethiopia; Ghana; Kenya; Niger; Senegal; South Africa; Zambia and Zimbabwe (Figure 5). Socio-economic data was collected from more than 10,000 farm surveys conducted in selected districts representative of the main agro-ecological zones and farming systems in each country. More details about the survey method and the data collected are found in Dinar et al. (2008).

The study used long-term average climate data on rainfall and temperature (climate normals). Two sources of climate data were used. Satellite data on temperature from the US Department of Defence Satellites (Basist et al., 2001) and precipitation data came from the Africa Rainfall and Temperature Evaluation System (ARTES) created by the National Oceanic and Atmospheric Association's Climate Prediction Center based on ground station measurements of precipitation (World Bank, 2003).

Data on stream flow and runoff (and other hydrological variables) was generated by continental hydrological model for Africa (Strzepek and McCluskey, 2007). Water flow measuring the movement of water between districts supplementing water collected from rainfall within the district is an important factor for African agriculture which faces water scarcity situations. The Food and Agriculture Organization (FAO) data on composition, coarseness and slope of major and minor soils in each district (FAO, 2003) was used to capture the effects of variations in soil attributes.

The farm survey which covered dryland and irrigated crop and livestock activities in different farming systems generated inadequate information on land rents in most countries in Africa, especially under the predominant smallholder conditions where land markets are not active if not completely absent. The study has therefore calculated net farm revenue as an alternative to land rents as the response variable. The farm survey provided information on many other socio-economic variables included in the analyses. 


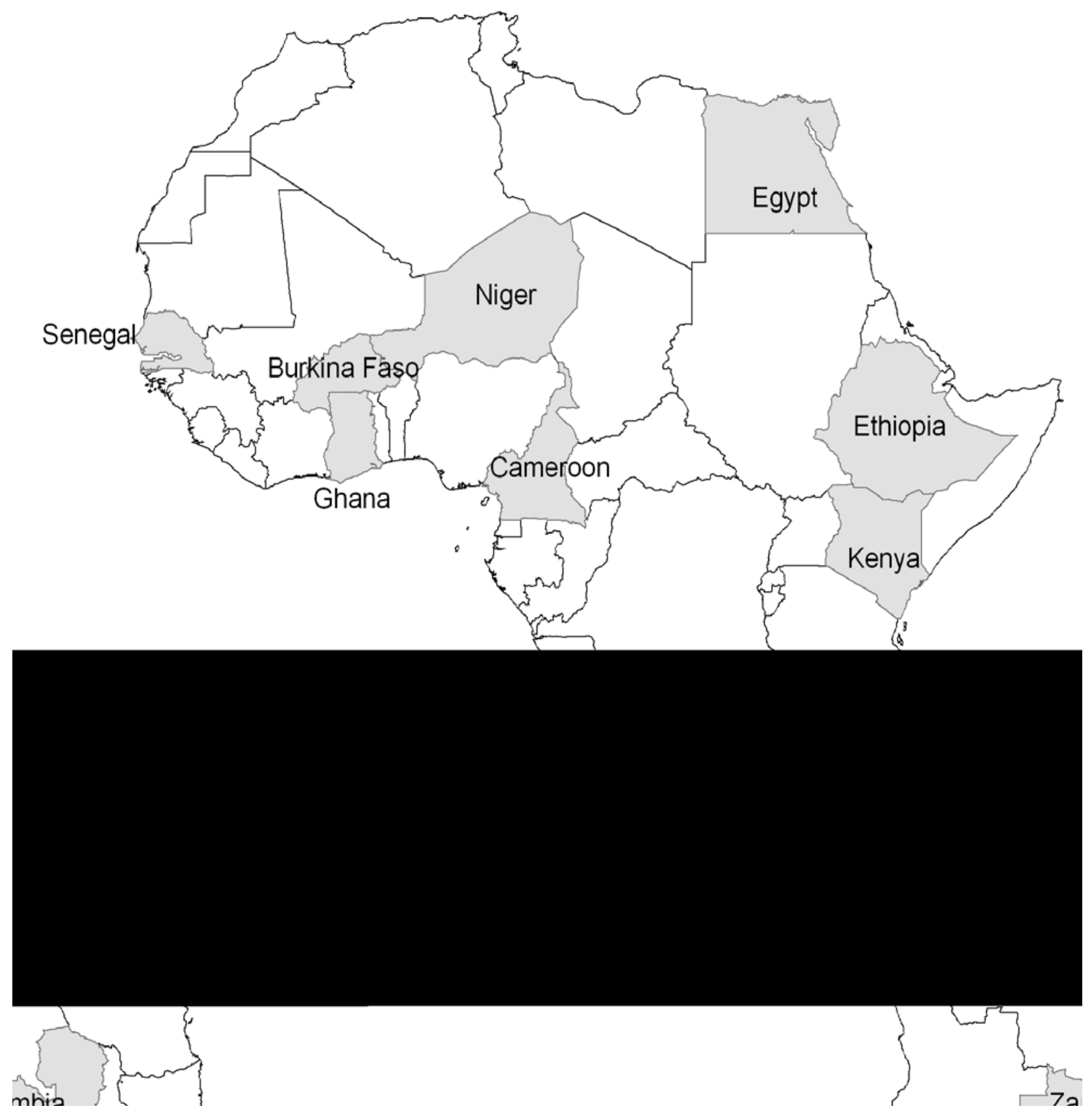

Figure 5. GEF Project Countries 


\subsection{Results of the economic impacts' analyses}

The cross-section analyses of economic impacts of CC on agriculture in Africa have been conducted at country and continental (regional) levels. Country level studies' results are not reported here but their details can be found in Dinar et al. (2008) and various reports on the project's website (www.ceepa.co.za/Climate_Change/project.html). Different empirical approaches and measures of net farm revenue were used to conduct the regional studies. Some regional analyses measured impacts on revenues from crops only (Kurukulasyuriya and Mendelsohn, 2008) and livestock only (Seo and Mendelsohn, 2008) while others quantified impacts on farm revenue from combined crop and livestock activities (Hassan and Nhemechena, 2008; Seo et al., 2008).

The Ricardian approach is traditionally based on analyzing net farm revenue or land value per hectare. As most farmers in Africa graze livestock on open access communal land it was very difficult to measure the amount of land farmers allocate to livestock production. Therefore, whereas crops-based analyses could calculate net revenue per hectare, livestock-based and combined crop-livestock analyses could only measure the response of net revenue at the farm level (i.e. making the unit of analysis the farm rather than hectare). The different studies also derived measures of impacts on dryland as well as irrigation agriculture and controlled for scale and some technology factors. Some of the regional analyses considered country fixed effects to account for effects of unmeasured inter-country variations (kurukulasyuriya et al., 2006). This section summarizes key results derived from all approaches used. All results are based on estimates of the parameters of the empirical Ricardian model in equation 2 above. The derived parameter estimates (for the various approaches mentioned) were used to calculate marginal impacts of changes in temperature and rainfall on net income of current farms as described in equations 3 and 4 and subsequently predict their future impacts based on certain climate change scenarios.

Results suggest that warming is harmful to crops but beneficial to cropping under irrigation (Table 1). The result indicating positive impacts of warming on irrigation crops 
is rather hard to digest and has thus been further investigated. This is done by excluding Egypt from the analyses since Egypt contributes $60 \%$ of the irrigation cropping in the sample of all countries and its agriculture relies entirely on irrigation under a relatively cooler climate and therefore considered the first suspect for biasing temperature effects on irrigated crop farming in Africa. This proved to be true as results excluding Egypt suggest that warming is harmful to crop farming both under dryland and irrigation conditions (Kurukulasuriya et al., 2006). As expected however, higher rainfall is beneficial to crop agriculture in Africa under both drayland and irrigated systems.

Warming appears to harm large scale while benefiting small scale livestock production systems (Table 1). This may be attributed to the fact that while large livestock farmers have better access to technology and capital they are usually more specialized in beef and diary cattle of mixed breeds being the most profitable animal species for them to raise but have lower tolerance to high temperatures. In contrast, small African livestock farmers rely mainly on small ruminants (goat and sheep) and local breeds of cattle that are much more adapted to high heat. Wetter conditions on the other hand harm both livestock production systems but damages are relatively higher for large farms (Table 1). One explanation for this is that under high rainfall regimes ecosystems shift from grassland to forests, animal disease (e.g. Trypanosomiasis, East Coast and Rift Valley fevers) becomes more prevalent, and sufficient water becomes available to support cropping activities. This is widely believed to be the main reason why most small African farmers do mixed crop-livestock farming and that most livestock production in Africa concentrates in relatively drier climates (Seo et al., 2008b).

Results of analyses combining both crop and livestock farming (all farms) confirm that, in general, warming is harmful while higher rainfall beneficial to African agriculture (Table 1). African farmers loose on average US\$ 39 per hectare for every ${ }^{0} \mathrm{C}$ rise in temperature but gain $\$ 2$ from one more $\mathrm{mm}$ of rainfall at current climate normals (i.e. prevailing long term temperature and precipitation averages). These results suggest that African agriculture has been much more sensitive to higher temperatures than rainfall fluctuations. 
Table 1. Marginal climate impacts on net revenue of current farms in Africa.

\begin{tabular}{|c|c|c|c|c|c|c|}
\hline & \multicolumn{3}{|c|}{ Specialized crops (US\$/ha) } & \multicolumn{2}{|c|}{ Specialized livestock (US\$/farm) } & All farms (\$/ha) \\
\hline & Africa & Irrigated & Rainfed & Small & Large & \\
\hline $\begin{array}{l}\text { Temperature }\left({ }^{0} \mathrm{C}\right) \\
\text { Precipitation }(\mathrm{mm})\end{array}$ & $\begin{array}{l}-28.3 \\
2.65\end{array}$ & $\begin{array}{l}33.6 \\
2.08\end{array}$ & $\begin{array}{l}-23.0 \\
2.02\end{array}$ & $\begin{array}{l}108.8 \\
-19.6\end{array}$ & $\begin{array}{l}-334.2 \\
-64.7\end{array}$ & $\begin{array}{l}-39.2 \\
2.02\end{array}$ \\
\hline
\end{tabular}

Note: Values are calculated at observed mean levels using estimated regression coefficients.

Source: Kurukulasuriya and Mendelsohn (2008), Seo and Mendelsohn (2008), Seo et al. (2008).

Table 2. Climate predictions of AOGCM models (2020 and 2100)

\begin{tabular}{|l|c|c|c|c|}
\hline Model & & Current averages & 2020 & 2100 \\
\hline CCC & \multirow{2}{*}{ Temperature (0C) } & 23.29 & $24.9(+1.6 \%)$ & $29.96(+6.7 \%)$ \\
\hline PCM & \multirow{2}{*}{ Precipitation (mm) } & 23.29 & $23.9(+0.6 \%)$ & $25.79(+2.5 \%)$ \\
\hline CCC & 79.75 & $78.8(-3.7 \%)$ & $65.08(-18.4 \%)$ \\
\hline PCM & & 79.75 & $89.8(+12.5 \%)$ & $83.18(+4.3 \%)$ \\
\hline
\end{tabular}


Probable future impacts of CC on agriculture in Africa are predicted using above estimated models' parameters simulated under climate projections of two contrasting Atmospheric-Oceanic Global Circulation Models (AOGCMs) for the years 2020 and 2100. These are projections of A1 scenarios of the Parallel Climate Model - PCM (Washington et al., 2000) and the Canadian Climate Centre - CCC (Boer et al., 2000). The PCM future climate predictions for 2020 and 2100 are relatively mild compared to more severe predictions under of the CCC model. While the two models agree on a warming trend the magnitudes of their predictions are very different and they also give contrasting precipitation scenarios. While CCC predicts decrease in rainfall PCM predicts increases in rainfall (Table 2). The two models predictions of rainfall also vary by region. PCM predicts large increases in rainfall in East and West Africa compared to its smaller forecasts for North, Central and Southern Africa. The CCC in contrast predicts higher rainfall in Central and West Africa but decreasing trends in the rest of Africa.

Impacts of these two AOGCM scenarios have been simulated and extrapolated from the 11 country sample to the entire continent ${ }^{2}$. Given the divergence between the two contrasting scenarios of used AOGCM models it is not surprising to get completely different impact results. The pessimistic CCC scenarios lead to significant losses in net farm revenue of African farmers that reaches up to $24 \%$ reductions whereas the optimistic PCM predictions of future climate in Africa suggest a gain of up to $46 \%$ by the not very far 2020 (Table 3). However predicted CCC damages tend to increase slightly to 27\% while gains predicted by the PCM moderate scenarios will be significantly lower in 2100 (Table 3). The sharp disagreement between predictions of these two contrasting AOGCM models is a good indication of how hard it is to predict future climate trends and how uncertain we remain on this front. A more critical implication of these results is clear need for downscaling predictions of global climate models to more regional and local scales, a major challenge facing present day climate science, especially in Africa where the capacity in this regard is seriously limited and calls for more aggressive effort and commitment.

\footnotetext{
${ }^{2}$ See details on extrapolation to calculate aggregate Africa-wide impacts in the above cited studies in Hassan, Dinar and Mendelsohn (2008) and www.ceepa.co.za/Climate_Change/project.html.
} 
Table 3. Simulated Africa-wide CC impacts of AOGCM climate scenarios in terms of change in net revenue for 2020 and 2100.

\begin{tabular}{|c|c|c|c|c|c|c|c|}
\hline & \multicolumn{3}{|c|}{$\begin{array}{c}\text { Specialized crops (Billion } \\
\text { US\$) }\end{array}$} & \multicolumn{2}{c|}{$\begin{array}{c}\text { Specialized livestock } \\
\text { (billion US\$) }\end{array}$} & $\begin{array}{c}\text { All farms (\% } \\
\text { change in net } \\
\text { revenue /ha) }\end{array}$ \\
\cline { 2 - 7 } & Africa & Irrigated & Rainfed & Africa & Small & Large & \\
CCC & -22.4 & 0.8 & -21.4 & -2.11 & 1.79 & -3.9 & $-24.0 \%$ \\
PCM & 58.7 & 0.4 & 57.3 & -9.76 & 0.02 & -9.78 & $46.0 \%$ \\
2100 & & & & & & & \\
CCC & -46.8 & 4.4 & -43.5 & 0.31 & 16.15 & -15.84 & $-27.0 \%$ \\
PCM & 69.2 & 4.6 & 50.8 & -11.06 & 2.68 & -13.74 & $12.0 \%$ \\
\hline
\end{tabular}

Source: Kurukulasuriya and Mendelsohn (2008), Seo and Mendelsohn (2008), Seo et al. (2008).

In spite of the uncertainities around what future climate will obtain for Africa the predictions reveal useful information about some interesting differences about important features of current agricultural production systems in Africa. Both scenarios for example show that irrigated crop agriculture is less sensitive to CC compared to dryland cropping. While irrigation seems to provide an effective buffer against CC, one should take predicted gains to irrigation crop agriculture with caution given our earlier results regarding the blurring effects of Egypt in the sample.

A different story unfolds with specialized livestock systems. Both models predict losses to specialized large scale livestock production in Africa. Similarly both models suggest that small livestock farmers are expected to benefit from predicted future climate for Africa. As explained earlier, this may be attributed to the better adaptability of animal species and breeds kept by small farmers in Africa compared to specialized large scale beef and dairy cattle systems. The net effect however is generally negative on the livestock sector (Table 3). The GEF studies also reveal very important differences in CC impacts between different regions and countries (Dinar et al., 2008 and Figure 6). 
Figure 6: Percentage change of farm net revenue with CCC 2100 Scenario

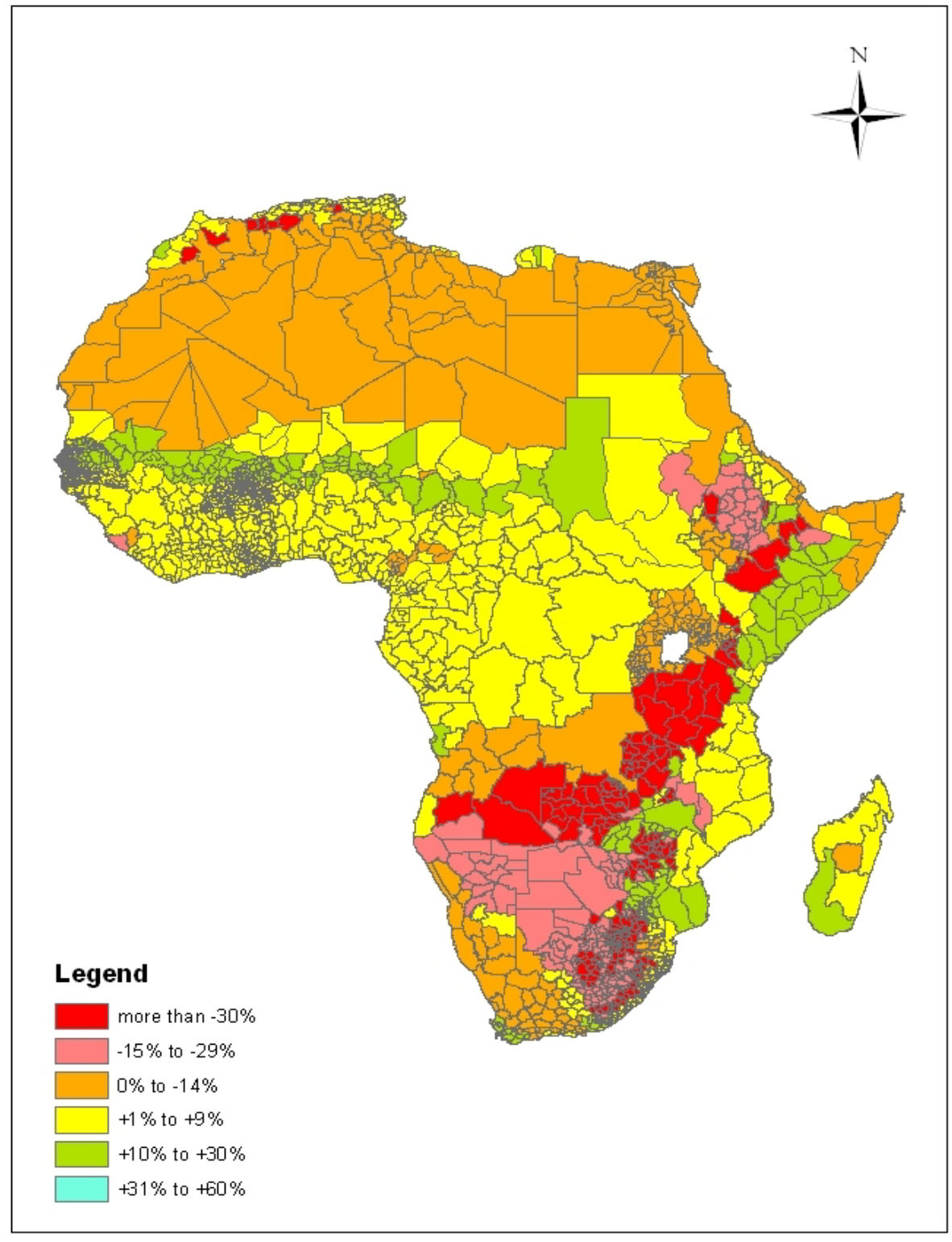

$0 \quad 3612$ Decimal Degrees

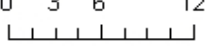




\section{Adaptation research methods and results}

The world has chosen to embark on two response actions to manage the consequences of CC: mitigation and adaptation. Mitigation measures aim to reduce annual global GHG emissions to stabilize their atmospheric concentrations at levels within the natural capacity of the earth system to absorb. This is to be achieved through international cooperation facilitated by the UN Framework Convention on CC (UNFCCC), Kyoto Protocol and other partnerships. While the benefits from mitigation are globally felt its implementation requires commitments from and collaboration between many countries. Adaptation on the other hand represents induced changes in natural and human systems in response to CC (indirect damage prevention measures). Motivations for adaptation responses mainly stem from local and often regional risks and priorities and consequently their benefits are realized at local or regional scales. In most cases however, adaptation responses represent actions taken by individuals, communities and governments.

While mitigation has been the focus and priority of climate policy in the past, the FAR of IPCC concludes that current mitigation efforts no matter how effective and rigorous, are not expected to have effects in the next few decades (IPCC, 2007). This is mainly due to the fact that current atmospheric concentrations of GHG are already by far higher than pre-industrial levels and the high residency of GHG in the atmosphere requiring long time lags before its effects obtain, i.e. several decades. Emphasis has therefore began to shift recently to adaptation measures since their effect are immediate and do not require long-time leads like mitigation actions. However, our knowledge and understanding of how human and natural systems have adapted to CC and how they will adapt to future climate is weak compared to the large advances in climate mitigation science and policy research. The knowledge gap is particularly big in developing countries, especially about observed and potential adaptation responses of vulnerable systems and populations such Africa's agriculture and its rural people.

Using the same dataset of the above described Africa-wide GEF study several attempts have been made to analyze and better understand adaptation strategies of African farmers. 
Various empirical models have been applied to analyze the nature and determinants of adaptation behavior of African farmers. The analyses considered all crop and livestock production activities separately and combined based on both farmers' perceptions and observed actual choices.

Analyses of farmers' perceptions about CC show that most farmers believe they have experienced abnormally drier and warmer climates over the past few decades. Farmers also report observed changes in timing of rains and frequency of droughts. These perceptions were then compared with actual weather stations' records in the various countries of the study. This analysis revealed that for most countries farmers' perceptions of recent warming and drying were consistent with weather stations records. A multinomial analysis of the probability to adapt to CC based on farmers' assessments (not actual choices) provided strong evidence that current climate highly influences the probability to adapt. Selection of adapted varieties, use of irrigation and changing planting dates are some of the key adaptation measures reported by farmers. Poor access to credit, markets, technology are among the main barriers to adaptation identified by farmers (Maddison et al., 2006).

Adapted versions (i.e. structural Ricardian) of the original cross-section method as well as multinomial choice models were applied to the GEF Africa dataset to analyze how CC influences actual farmers' choices of various adaptation measures. Key adaptations considered included: selection of crop and livestock types (Seo and Mendelsohn, 2008; Kurukulasuriya and Mendelsohn, 2008b), choice of mono or multiple cropping, specialized or mixed crop and livestock farming under dryland or irrigated systems (Hassan and Nhemachena, 2008b). Results of adaptation analyses reveal that choice of livestock species, switching of crops, choice of irrigation and mixing of crops and livestock are important adaptation actions made by African farmers. The analyses confirm that farmers' adaptation decisions are highly sensitive to both temperature and precipitation (after controlling for the effects of other factors of key relevance).

African farmers raising livestock were found to switch away from specialized large scale beef and dairy cattle to small ruminants such as goats and sheep as temperatures get 
warmer. These results suggest that sheep and goat systems which are predominantly local breeds are more adapted to the warmer African climate compared to the cattle-based systems where hybrid species dominate. The same effects obtain under higher rainfall confirming the earlier results of economic damages that hot and wet future climates will be harmful to specialized large scale beef and dairy cattle systems. This contrasts with the findings of studies in the US which suggest that livestock are not climate sensitive. In addition to the cooler climates in which livestock in the US and other temperate regions are reared compared to Africa, the difference in the capital intensity of livestock management (i.e. protected feedlots versus open access grazing) is another important factor explaining the contrasting differences in climate sensitivity.

The studies found African farmers to be making rational choices in terms of selecting crop types suited for their local climate conditions. For example, mixed maize systems (beans and groundnuts) dominate cooler and wetter regions of Africa, whereas cowpea, millet and sorghum are chosen in hot and dry regions. African farmers were also found to often choose crop combinations to survive the harsh conditions in Africa. Warmer temperatures seem to induce switching away from mono-cropping and promote adoption of irrigation, multiple cropping and mixed crop-livestock systems. More rainfall on the other hand reduces the probability of choosing irrigation suggesting that increased precipitation would be beneficial to dryland crops' systems. The results however suggest that choice of irrigation and mono or mixed crop-livestock systems is more sensitive to warming than influences of changes in rainfall. As many regions in Africa are already warm and dry, any further warming is expected to require various irrigation and multiple and mixed crop-livestock adaptation measures. This also implies that the risk of monocropping under dryland is higher with warming in general. Adoption of multiple cropping and mixed crop-livestock systems provides farmers more flexibility across climates than growing a single crop. Farmers' education, improved access to information, credit, markets, irrigation, technology and capital were found to be key enabling factors for promoting adaptation. Improving access to technology such as electricity and machines increases the chances of farmers taking up adaptation measures. Better access to markets reduces transport and other market related transaction costs and enables farmers to buy new crop varieties, new irrigation technologies and other important inputs they may need 
to change their practices to cope with predicted changes in future climate. The GEF adaptation analyses revealed that market development in Africa tends to concentrate within irrigation agriculture and hence the need for improving the relatively poor access of dryland farmers to markets.

\section{Policy Challenges and research agenda}

Clear warming trends, increased incidence of extreme weather events particularly droughts and large fluctuations in precipitation patterns, especially shortening of season and shifts in timing of rain have been observed over the past few decades in Africa. The observed CC trends have impacted significantly on African agriculture in the past and expected to worsen in future. Results reported above from an Africa wide study confirm that African agriculture and the welfare of its rural population are vulnerable to CC. The sensitivity is relatively higher to warming compared to changes in rainfall patterns. Vulnerability also varies significantly by climate region, farming system (e.g. various crop-livestock combinations) and level of technology use, especially irrigation.

Significant economic damages of CC were predicted to fall on African agriculture and the welfare of its rural communities measured as losses in net farm revenue that could reach up to $25 \%$ of current levels if the climate in Africa will be $1.6 \%$ warmer and $3.7 \%$ dryer (CCC scenario) over the next 12 years, i.e. up to 2020. This indicates the urgent need for action now to manage the expected negative consequences of CC. However, under less pessimistic future climate scenarios (e.g. PCM) African agriculture is predicted to gain (under very moderate warming and increase in rainfall). The contrasting results of these two CC scenarios indicate the high uncertainty in our knowledge about future climates, especially rainfall. This is one area where there are major contemporary challenges to climate science research especially climate forecasting in Africa. Since these predictions were based on GCCMs one priority agenda for managing CC and its consequences is clearly development of sufficient capacity to improve downscaling of global and regional climate models to appropriate local scales for Africa. Climate forecast models that are 
able to attach probability distributions to predicted outcomes are necessary in order to increase confidence in their predictions.

More over, predicted economic impacts have been quantified using parameter estimates of cross-section (Ricardian) models that maintain some restrictive assumptions about the future. One strong assumption of this approach is that future economic structures and behavior will continue the same way as in the observed past. For example, while these models employ predictions of future climates they do not use projections of future technology and prices. In addition, the models used to measure economic impacts in the reported studies did not control for the effect of carbon fertilization which would be beneficial in terms of inducing higher crop yields. There is therefore a need for more comprehensive and dynamic assessment models such as dynamic climate CGE's that incorporate such critical components and processes. Also, economic impact assessment analyses carried under these GEF studies were based on mean levels of climate attributes and did not include climate variance variables. One important extension of the reported economic impact assessment models is to incorporate treatment of climate variability to better deal with the economics of risk and uncertainty being key features of CC and its impacts.

Predictions indicate that the highest risk of future damages due to CC is associated with specialized crop and livestock farming (mono systems) particularly under dryland conditions in arid and semi-arid regions. Use of irrigation, multiple crops and animal species and mixed crop-livestock production systems in these regions appear to mitigate expected damages. Large scale cattle-based dairy and beef systems were found to be more sensitive to both high temperature and rainfall compared to the more adapted sheep and goat species. These results have important implications for research and climate policy.

The above suggest that it will be difficult to support an African green revolution with the current high reliance on dryland systems (more than 95\% of the land) given predicted harsh future climates (warmer and dryer projections) for most of the dryland areas in 
Africa. Expanding irrigation is certainly one potentially effectice action that would mitigate water stress and reduce vulnerability to CC. Although currently Africa has very little irrigation (less than 5\% compared to more than $30 \%$ of the land in Asia) predicted declines in water availability puts serious limits on the irrigation potential. The other challenge is the high cost of developing new water supply and irrigation schemes given current and expected worsening scarcity in the future. Development of successful new irrigation projects (water storage and conveyance infrastructure) in Africa has been estimated to cost between \$ 3,600 and 5,700 per hectare (ha) at 2000 prices (Inocencio et al., 2005). Although these investments are typically considered to provide services of public good nature and hence financed through government funds, the observed difference between net farm revenue per ha under irrigation and dryland farming suggests that there is a huge potential for recovering most of these costs from farmers. However, a good potential also exists for promoting private investment by farmers in more efficient irrigation (e.g. drip irrigation) and water use methods (green houses) on high value export crops. This will require provision of the right incentive structure and technology research investments. Investment by farmers with the appropriate public support in various ways of water harvesting will be necessary for small holder farmers in these regions.

Dryland agriculture, particularly in marginal areas of Africa is practiced on inherently low soil fertility and depleted nutrient stocks under low technology, which makes it a formidable challenge to future agricultural research and climate policy in Africa to reduce its vulnerability to predicted harsh future climates. This will require substantial public investments in development of crop varieties and animal breeds that are tolerant to heat, water and low fertility stresses, and in building roads and marketing infrastructures that will improve access to critical inputs (e.g. fertilizer) and output trade. Appropriate complementary policies will be necessary to make this work.

The high vulnerability of sole cropping and specialized large scale cattle-based dairy and milk systems to warming suggests that agricultural development strategies and planning must consider potential shifts in suitable climate zones for these activities with CC. Traditional agricultural development models and modernization strategies that typically 
promote expansion in commercial mono-cropping such as tea, coffee, sugar cane and tobacco plantations and large scale beef and dairy farming should therefore consider identified vulnerabilities to CC shifts. Research on more adapted crop varieties and animal breeds and crop management and animal husbandry practices that would reduce such vulnerabilities is needed in face of CC and its predicted consequences. This essentially requires mainstreaming climate sensitivity as an integral component of all agricultural and broader economic development planning and policy design.

While the expected damages are large, adaptive capacity of many African countries is very low. Although African farmers have been observed to use various coping measures and strategies in face of CC it is clear that many farming systems and communities in Africa face serious limiting conditions which reduce their ability to adapt and hence increase their vulnerability. Among the key factors found to constrain African farmers' ability to adopt effective adaptation measures are poor access to information (climate, production and market), capital, technology and markets. Policies aimed at promoting farm-level adaptation need to emphasize the critical role of farmers' education; provision of improved climate, production and market information and the means to implement adaptations through affordable credit facilities. Other needed public interventions to help promote adaptation measures and reduce vulnerability include insurance against climate risks to farmers and provision of safety nets. 


\section{References}

Adams RM, 1999. On the search for the correct economic assessment method-an editorial comment, Climatic change 41, 363-370.

Adams RM, Hurd BH, Lenhart S and Leary N, 1998. Effects of global change on agriculture: an interpretative review, Climate Research 11, 19-30.

Adams RM, Fleming RA, Chang CC, McCarl BA, and Rosenzweig C, 1995. A reassessment of the economic impacts of global change on U.S. agriculture. Climate Research 30, 147-167.

Adams, R.M., McCarl, B.A. and others, 1998. Climate Change and US Agriculture: some further evidence, Report prepared for the Electric Power Research Institute as part of the Agricultural Impact Project of the Climate Change Impacts Program (CCIP).

Basist, A., Peterson, N., Peterson, T., and Williams, C. 1998. Using the Special Sensor Microwave Imager to monitor land surface temperature, wetness, and snow cover” J. Applied Meteorology 37, 888-911.

Benson, C. and Clay, E. 1998. The impact of drought on sub-Saharan economies, Word Bank Technical Paper 401, World Bank, Wasington DC

Boer, G., G. Flato, and D. Ramsden. 2000. A Transient Climate Change Simulation with Greenhouse Gas and Aerosol Forcing: Projected Climate for the $21^{\text {st }}$ Century, Climate Dynamics 16, 427-450.

Chang CC (2002). The potential impact of climate change on Taiwan's agriculture, Agricultural Economics 227, 51-64.

Darwin R (1999). A farmer's view of the Ricardian approach to measuring agricultural effects of climate change, Climatic change 41, 371-411.

Darwin RF, Tsigas M, Lewandrowski J and Raneses A, 1995. World agriculture and climate change: economic adaptations, Agricultural Economic Report Number 703, United States Department of Agriculture, Economic Research Service, Washington DC.

Darwin RF, Lewandrowski J, McDonald B and Tsigas M, 1994. Global climate change: analysing environmental issues and agricultural trade within a global context. In: Sullivan J (ed), Environmental policies: implications for agricultural trade, Foreign agricultural economic report number 252, United States Department of Agriculture, Economic Research Service, Washington DC.

Desanker, P.V. 2002. Impact of Climate Change on Africa. Center for African Development Solutions, Johannesburg, South African, and University of Virginia, Charlottesville, VA 
Desta, S. and L. Coppock, 2004: Pastoralism under pressure: tracking system and change in southern Ethiopia. Hum. Ecol. 32, 465 - 486.

Dinar A, Hassan R, Mendelsohn R and Benhin J, 2008. Climate Change and African Agriculture: Impact Assessment and Adaptation Strategies. Earthscan, London.

Downing, T.E. 1992. Climate change and vulnerable places: Global food security and country studies in Zimbabwe, Kenya, Senegal and Chile”, Research Paper No. 1, Environmental Change Unit, University of Oxford, Oxford, 54pp

Deressa T., R. Hassan \& D. Poonyth. 2005. Measuring the economic impact of climate change on South Africa's sugarcane growing regions. Agrekon 44(4): 524-542.

Durand, W. (2006), Assessing the impact of climate change on crop water use in South Africa, CEEPA DP28.

du Toit A.S., M.A. Prinsloo, W. Durand and G. Kiker. 2002. Vulnerability of maize production to climate change and adaptation in South Africa. Combined Congress: South African Society of Crop Protection and South African Society of Horticultural Science, Pietermaritsburg, South Africa.

Easterling WE III, Crosson PR, Rosenberg NJ, McKenny MS, Katz LA and Lemon KA (1993) Paper 2. Agricultural impacst of and response to climate change in the MissouriIowa-Nebraska-Kansas (MINK) region. Climate Research 24, 23-61.

FAO (Food and Agriculture Organization), 2003. The digital soil map of the world: Version 3.6 (January), Rome, Italy.

Fischer, G. and H. van Velthuizen. 1996. "Climate Change and Global Agricultural Potential: A Case of Kenya” IIASA Working Paper WP-96-071.

Gbetibouo, G., and R. Hassan. 2005. Measuring the Economic Impact of Climate Change on Major South African Field Crops: A Ricardian Approach. Global and Planetary Change 47(2-4): 143-52.

Hassan R. and C. Nhemachena, 2008. Measuring the economic impact of African agriculture. Draft report, CEEPA, University of Pretoria.

Hassan, R. and C. Nhemachena, 2008b. Determinants of climate adaptation strategies of African farmers: Multinomial choice analysis, African Journal Agriculture and Resource Economics (AfJARE), Volume 2 No. 1 (March 2008).

Hassan, R., A. Dinar and R. Mendelsohn (eds.), 2008. Climate Change and African Agriculture, Special Issue of the African Journal Agriculture and Resource Economics (AfJARE), Volume 2 No. 1 (March 2008). 
Hulme M., R.M. Doherty, T. Ngara, M.G. New \& D. Lister. 2001. African climate change: 1900-2100, Climate Research 17, 145-168.

IAC (InterAcademy Council) Report. 2004. Realizing the promise and potential of African agriculture. Royal Netherlands Academy of Arts and Sciences, NL-1000 GC Amsterdam, The Netherlands.

Iglesias A, Rosenzweig C and Pereira D, 1999. Agricultural impacts of climate change in Spain: developing tools for a spatial analysis, Global Environmental Change 10, 69-80.

Incencio, A., M. Kikuchi, D. Merrey, M. Tonosaki, M. Maruyama, I. de Jong, H. Sally and F. Penning de Vries, 2005. Lessons from irrigation investment experiences: Costreducing and performance-enhancing options for Sub-Saharan Africa. Report 6, International Water Management Institute-IWMI, Colombo

IPCC (Intergovernmental Panel on Climate Change), 2007. Synthesis Report: Summary for Policy Makers. Cambridge University Press, Cambridge, UK.

IPCC (Intergovernmental Panel on Climate Change), 2007a. Africa. Cambridge University Press, Cambridge, UK.

IPCC (Intergovernmental Panel on Climate Change), 2007c. Impacts, Adaptations, and Vulnerability, Fourth Assessment Report, Cambridge University Press, Cambridge, UK.

IPCC (Intergovernmental Panel on Climate Change), 2001. Climate Change 2001: Impacts, Adaptation, and Vulnerability, Intergovernmental Panel on Climate Change, Cambridge University Press, Cambridge, UK

Kurukulasuriya, P., R. Mendelsohn, R. Hassan, J. Benhin, M. Diop, H. M. Eid, K.Y. Fosu, G. Gbetibouo, S. Jain, , A. Mahamadou, S. El-Marsafawy, S. Ouda, M. Ouedraogo, I. Sène, D. Maddision, N. Seo and A. Dinar. 2006. "Will African Agriculture Survive Climate Change?” World Bank Economic Review 20: 367-388.

Kurukulasuriya, P. and R. Mendelsohn, 2008b. Crop switching as adaptation strategy. African Journal Agriculture and Resource Economics (AfJARE), Volume 2 No. 1 (March 2008).

Kurukulasuriya, P. and S. Rosenthal, 2003. Climate Change and Agriculture A Review of Impacts and Adaptations. Environment Department Papers, Paper 91. Washington DC: World Bank, June 2003.

Kurukulasuriya, P. and R. Mendelsohn. 2008. A Ricardian Analysis of the Impact of Climate Change on African Cropland. African Journal Agriculture and Resource Economics (AfJARE), Volume 2 No. 1 (March 2008). 
Lotsch, Alexander, 2006. Modeling Drought Hazards in Africa. Center for Environmental Economics and Policy for Africa, University of Pretoria, South Africa, CEEPA DP14.

Maddison, D., 2006. The perception of and adaptation to climate change in Africa, CEEPA Discussion Paper No. 10, Centre for Environmental Economics and Policy in Africa -CEEPA, University of Pretoria

Magadza C.H.D. 1994. Climate Change, some likely multiple impacts in Southern Africa, Food Policy, Volume 19 (2): 165-191.

Makadho JM, 1996. Potential effects of climate change on corn production in Zimbabwe. Climate Research 6(2): 147-151.

Mendelsohn R \& Dinar A, 1999. Climate change, agriculture, and developing countries: Does adaptation matter? The World Bank Research Observer 14(2): 277-293.

Mendelsohn, R., W. Nordhaus and D. Shaw. 1994. "The Impact of Global Warming on Agriculture: A Ricardian Analysis" American Economic Review 84: 753-771.

Mendelsohn, R. and W. Nordhaus. 1996. "The Impact of Global Warming on Agriculture: Reply” American Economic Review 86: 1312-1315.

Mendelsohn, R., Dinar, A. and Dalfelt, A. 2000. Climate change impacts on African Agriculture, World Bank, Washington, DC (Mimeo).

Muchena, P. 1994. "Implications of climate change for maize yields in Zimbabwe”, in Rosenzweig, C. and Iglesias, A (eds) Implications of Climate Change for International Agriculture: Crop Modeling Study. US Environmental Protection Agency, Washington DC

Molua EL, 2002. Climate variability, vulnerability and effectiveness of farm-level adaptation options: The challenges and implications for food security in southwestern Cameroon. Environment and Development Economics 7: 529-545.

OFDA/CRED, International Disaster Database (www.crd.be/emdat)

Onyeji, S.C. and Fischer, G. 1994. "An economic analysis of potential impacts of climate change in Egypt”, Global Environmental Change and Policy Dimensions 4(4): $281-299$.

Ricardo, David, 1817. The Principles of Political Economy and Taxation. London, John Murray.

Rinke, A. Sarr and P. Whetton, 2007: Regional climate projections. Climate Change 2007: The Physical Science Basis. Contribution of Working Group I to the Fourth 
Assessment Report of the Intergovernmental Panel on Climate Change. S. Solomon, D. Qin, M. Manning, Z. Chen, M. Marquis, B. Averyt, M. Tignor and H.L. Miller, Eds., Cambridge University Press, Cambridge, 847 - 940.

Rosenzweig C and Parry M (1994), Potential impacts of climate change on world food supply, Nature 367, 133-138.

Sanghi A, Mendelsohn R \& Dinar A, 1998. The climate sensitivity of Indian agriculture. In Dinar A et al., (eds), 1998. Measuring the impact of climate change on Indian agriculture. World Bank Technical paper 402. Washington, DC.

Schimmelpfennig D, Lewandrowski J, Reilly J, Tsigas M and Parry I, 1996., Agricultural Adaptation to Climate Change: Issues of Long-run Sustainability, Agricultural Economic Report No. (AER740), United States Department of Agriculture, USA.

Seo, N. and R. Mendelsohn. 2008. Climate Change Impacts and Adaptations on Animal Husbandry in Africa, African Journal of Agricultural and Resource Economics (AfJARE), Volume 2, No. 1 (March 2008).

Seo N, R. Mendelsohn, A. Dinar, R. Hassan and P. Kurukulasuriya, 2008. A Ricardian Analysis of the Distribution of Climate Change Impacts on Agriculture across AgroEcological Zones in Africa, World Bank Policy Paper, Washington, DC.

Stern, N., 2007. The Economics of Climate Change: The Stern Review. Cambridge University Press, Cambridge. 692pp.

Strzepek, Kenneth and Alyssa McClusky, 2006. District Level Hydroclimatic Time Series and Scenario Analysis to Assess the Impacts of Climatic Change on Regional Water Resources and Agriculture in Africa. CEEPA DP13.

Thornton, P.K., P.G. Jones, T.M.Owiyo, R.L. Kruska, M. Herero, P. Kristjanson, A. Notenbaert, N. Bekele and Co-authors, 2006: Mapping climate vulnerability and poverty in Africa. Report to the Department for International Development, ILRI, Nairobi, 200pp.

Tol, R. 2002. "Estimates of the Damage Costs of Climate Change. Part 1: Benchmark Estimates” Environmental and Resource Economics 21: 47-73.

UNEP-GRID-Arendal. 2002. (http://www.grida.no/climate/vitalafrica/english (Accessed

11 March 2006).

World Bank, 2003. Africa Rainfall and Temperature Evaluation System. World Bank, Washington DC.

World Bank, 2008. World Development Report 2008. World Bank, Washington DC. 
Washington, W., et al. 2000. "Parallel Climate Model (PCM): Control and Transient Scenarios” Climate Dynamics 16: 755-774.

Yates DN and Strzepek KM. An assessment of integrated climate change impacts on the agricultural economy of Egypt, Climatic change 38, 261-287. 